\title{
PLANEJAMENTO TRIBUTÁRIO: ORIENTAÇÃO AO CONTRIBUINTE NA ESCOLHA DAS MODALIDADES TRIBUTÁRIAS - SIMPLES NACIONAL LUCRO PRESUMIDO, E LUCRO REAL
}

\section{ARTIGO ORIGINAL}

REIS, Valeska Alves Oliveira ${ }^{1}$, CELIS, Paola Cristina Sandoval ${ }^{2}$, ROBERTO, José Carlos Alves ${ }^{3}$, SERRA, Meg Rocha da Cunha ${ }^{4}$, LOPES, Nelânia Ferreira ${ }^{5}$

REIS, Valeska Alves Oliveira. Et al. Planejamento tributário: orientação ao contribuinte na escolha das modalidades tributárias - simples nacional lucro presumido, e lucro real. Revista Científica Multidisciplinar Núcleo do Conhecimento. Ano 06, Ed. 10, Vol. 03, pp. 24-45. Outubro de 2021. ISSN: 24480959 , Link de acesso:

https://www.nucleodoconhecimento.com.br/contabilidade/modalidades-tributarias,

DOI: 10.32749/nucleodoconhecimento.com.br/contabilidade/c

\section{RESUMO}

Dentre os meios que podem ser utilizados para conseguir essa vantagem competitiva frente aos competidores está o Planejamento de Tributos a capacidade de gestão uma vez que, que o crescimento dos lucros na sociedade empresária será consequência de tomadas de decisões inteligentes que devem ser realizadas pelas pessoas responsáveis pela gestão, sobretudo no que diz respeito aos tributos. $O$ presente artigo tem como finalidade mostrar a maneira que o planejamento de tributos contribui positivamente na escolha de uma das modalidades tributárias,

\footnotetext{
${ }^{1}$ Graduando do curso de Contabilidade. Centro Universitário Fametro.

${ }^{2}$ Graduando do curso de Contabilidade. Centro Universitário Fametro.

${ }^{3}$ Orientador. Mestre em Engenharia de produção. Especialista Logística empresarial. Graduado em Administração com Ênfase em Marketing. Centro Universitário Fametro.

${ }^{4}$ Orientadora. Mestra em Engenharia de Processos Industriais pela UFPA, especialista em Controladoria e Auditoria Contábil pelo Ciesa, Graduada em Ciências Contábeis pelo Centro Universitário do Norte. Graduada em Ciências Econômicas pelo Centro Universitário do Norte. Centro Universitário Fametro.

${ }^{5}$ Orientadora. Especialista em Auditoria Contábil, Financeira e Tributária e Graduada em Ciências Contábeis. Centro Universitário Fametro.
}

RC: 98678

Disponível em:

https://www.nucleodoconhecimento.com.br/contabilidade/modalidades-tributarias 
apontando os regimes tributários vigentes. Para dar suporte ao estudo foi levantada a seguinte pergunta problema: como o planejamento tributário pode ajudar o contribuinte na escolha das modalidades tributárias no simples nacional, lucro presumido e lucro real? Quanto aos objetivos da pesquisa: mostrar a relevância do planejamento de tributos para a deliberação referente a escolha dos regimes, descrever o conceito dos regimes de tributação, apontando suas características e comparar os regimes de tributação vigentes, para que as sociedades empresárias possam ser orientadas e tenham clareza no enquadramento da empresa. $O$ estudo foi realizado tendo como objeto de estudo pesquisas bibliográficas, artigos e livros a partir da pesquisa qualitativa. Conclui-se que a necessidade do auxílio e orientação de um contador tributarista, já que este tem o conhecimento da legislação, pois ele analisará todas as informações geradas e fornecidas pela empresa, levando-o a indicar qual a melhor modalidade a que ela se enquadra.

Palavras-chave: Planejamento tributário, Legislação, Lucro real.

\section{INTRODUÇÃO}

À medida que o tempo passa, a competitividade entre as empresas aumenta devido a tecnologia que vai se desenvolvendo nas empresas que oferecem o mesmo produto e então ocorre a necessidade investir cada vez mais em seus diferenciais com o propósito de se distanciar da concorrência e, consequentemente, alcançar uma posição melhor no mercado. Dentre os meios que podem ser utilizados para conseguir essa vantagem competitiva frente aos competidores está o Planejamento de Tributos, a capacidade de gestão uma vez que, o crescimento dos lucros na sociedade empresária será consequência de tomadas de decisões inteligentes que devem ser realizadas pelas pessoas responsáveis pela gestão, sobretudo no que diz respeito aos tributos.

A conduta de planejar, abrange estudos preliminares relacionados à atividade mercantil que será desempenhada. Em seguida, deverão ser determinadas as metas de curto e/ou longo prazo, além de todas as táticas que serão utilizadas para que 
seja possível alcançar os objetivos almejados. É nesse formato que o planejamento de tributos se encontra presente em algumas das sociedades empresárias. Em um círculo social com uma alta competitividade, o planejamento proporciona opções mais econômicas legais e proporciona métodos tributários baseados na norma que permite sua permanência no mercado.

Conforme estabelecido no art. 153 da Lei o 6.404/1976, que dispõe sobre a sociedade por ações, "o administrador da companhia deve empregar, no exercício de suas funções, o cuidado e diligência que todo homem ativo e probo costuma empregar na administração dos seus próprios negócios" (BRASIL, 1976), em outras palavras, a disposição presume uma interpretação que, por parte dos administradores, é essencial um planejamento de tributos para um ótimo gestor. Desta forma, é necessário que o gestor possua uma ótima compreensão em relação aos tributos atuais, e as normas que estão em vigor no País, se embasando na Constituição Federal - CF, local em que estão determinadas as normas gerais de tributos.

Pode-se mencionar duas formas de se diminuir as obrigações de tributos, o primeiro tipo é no formato legal, tópico que está sendo abordado neste trabalho, que é realizado por meio do planejamento de tributos, também denominado como elisão fiscal. O segundo tipo é denominado evasão tributária, expressada por meio da sonegação de tributos. O planejamento de tributos é um formato legal que tem como propósito diminuir a carga tributária de uma sociedade empresária, onde o contribuinte tem a autonomia de arrumar seu empreendimento no melhor formato em que queira adequar as suas operações, objetivando sempre a diminuição das despesas e observando a legislação, procedendo de maneira permitida.

Conforme o Instituto Brasileiro de Planejamento e Tributação - IBPT (2011), no país, em média $33 \%$ da receita dos empresários se relaciona aos dispêndios com tributos. Isto posto, é de suma importância que todos os contribuintes exerçam seu empreendimento a economia lícita. Recomenda-se organizar a tributação por questão de permanência e longevidade no mercado consumidor. A pessoa 
responsável pela gestão dos tributos deverá conduzir-se de forma correta, em favor do que é vantajoso para a perpetuidade da empresa.

De acordo com Graziose (2010), afirma que para a elaboração da pergunta norteadora de pesquisa "A pergunta deve ser específica, clara, explícita e operacional, uma pergunta de pesquisa é a declaração de uma indagação específica que o pesquisador deseja responder para abordar o problema de pesquisa". Assim surgiu o questionamento: Como o planejamento tributário pode ajudar o contribuinte na escolha das modalidades tributárias no simples nacional, lucro presumido e lucro real?

Porque o planejamento de tributos é uma coleção de táticas legais que objetivam a redução dos dispêndios com tributos, a sociedade empresária escolhe a possibilidade ideal de tributação objetiva, para atenuar o efeito dos tributos em relação ao fluxo de caixa. $\mathrm{Na}$ falta do planejamento de tributos as sociedades empresariais se submetem a um elevado dispêndio de tributos no qual na maioria das vezes não possuem condições financeiras, como consequência as sociedades empresárias buscam maneiras de diminuir o impacto dos tributos decorrentes de um sistema tributário que sobrecarrega e afeta o lucro e, consequentemente, sua longevidade no mercado.

Portanto, este estudo propõe mostrar a maneira que o planejamento de tributos contribui positivamente no resultado financeiro das empresas, apontando a maneira que o planejamento de tributos contribui positivamente na escolha de uma das modalidades tributárias vigentes. Bem como, expor a relevância do planejamento de tributos para a deliberação referentes a escolha dos regimes, descrevendo o conceito dos regimes de tributação, apresentando suas características e comparar os regimes de tributação vigentes, para que as sociedades empresárias possam ser orientadas e tenham clareza no enquadramento da empresa. O estudo foi realizado tendo como objeto de estudo pesquisas bibliográficas, artigos e livros a partir da pesquisa qualitativa. 


\section{FUNDAMENTAÇÃO TEÓRICA}

A etapa do referencial teórico faz parte de todo trabalho científico, pois é a partir desta etapa que será apresentado estudos sobre o tema que será desenvolvido ao longo do estudo, ou especificamente sobre o problema, já realizados por outros autores (VERGARA, 2016), pois o escritor do estudo fará uma revisão literária de outras publicações, a partir desse ponto pode-se começar a dissertar e discutir os tópicos que serão abordados no trabalho, onde apresentará suas discordâncias para que assim se faça uma reconstrução, atualizando o trabalho científico.

\subsection{PLANEJAMENTO TRIBUTÁRIO}

As organizações buscam reduzir o maior custo possível ao que se refere com recolhimento de tributos, o tributo é definido pelo art. $3^{\circ}$ da Lei $n^{\circ} 5.172 / 1996$ do CTN como uma prestação compulsória a ser paga ao Estado, pois ela influencia diretamente no valor do produto ou do serviço que eles oferecem, pois sabe-se que o mercado de hoje em dia é muito competitivo, e o consumidor opta pelo preço mais acessível.

Dessa maneira, o empresário está na obrigação de cumprir conforme o previsto, devendo acatar respeito ao recolhimento do tributo, já que independente de sua vontade, deve desembolsar em moeda ou com bens de valor, sendo provenientes de atos lícitos. Para o contribuinte é uma desvantagem ter essa alta carga tributária, a qual se torna uma despesa na empresa, afetando diretamente nas receitas, já que haverá uma redução no ganho da entidade.

Nesse contexto surge a necessidade de uma gestão dos recursos financeiros de uma entidade jurídica ou pessoa física, isto com o fim de avaliar a regularidade da sua gestão tributária e visar a economia fiscal, dessa forma o planejamento tributário surge como uma necessidade básica dos contribuintes. Chaves (2017) ressalta que o planejamento tributário de uma empresa depende da situação geral em que se encontra, o contador ou administrador deve avaliar e analisar a entidade como um 
todo e fornecer um planejamento de baixos custos inclusive tributários. Vello e Martinez (2014) apontam como um estudo que ajuda na redução de despesas com tributos de uma maneira lícita, possibilitando eficiência nos gastos fiscais e aumentando assim a competitividade da empresa.

Pois é um meio que as empresas optam para que se prevejam do que ocorrerá no futuro, buscando mecanismos que permitam diminuir o desembolso financeiro. Assim, as entidades se antecipam a organizar suas atividades antes que ocorra o fato gerador que nesse caso é o tributo, dessa forma as entidades poderão minimizar suas despesas de forma geral. Para que ocorra o cumprimento corretamente, a estruturação do planejamento tributário o profissional de contabilidade deve ter a habilidade de interpretar, aplicar e fazer cumprir a legislação tributária vigente no país. Pois, para que a empresa aufira de isenções e benefícios fiscais, a mesma tem que estar em regra com o Fisco.

Partindo destas informações pode-se afirmar que as entidades necessitam ser orientadas, para evitar que sejam punidas pelos órgãos fiscalizadores, tanto financeiramente como patrimonial. O contador além de guiar sobre em qual das modalidades a empresa se enquadra, também dará ciência sobre a obrigatoriedade das normas contábeis e das normas de legislação fiscal. Para isso, as organizações devem fazer seu planejamento tributário no começo do exercício, tendo já definido o regime adotado.

\subsubsection{ELISÃO E EVASÃO FISCAL}

A elisão fiscal é uma técnica contábil que possibilita adequar uma sociedade empresária na formatação que dê mais vantagem em relação ao recolhimento de tributos, de forma que não cometa qualquer ato ilegal. $O$ termo Elisão possui derivação do latim que significa ato ou efeito de suprimir ou eliminar o que está disposto na legislação. Desta forma, para as sociedades empresárias contribuintes, praticar elisão fiscal vêm se tornando uma ferramenta especial na redução do custo tributário. A gestão de tributos está associada com a elisão. $O$ ato de elidir é o ato de

RC: 98678

Disponível em:

https://www.nucleodoconhecimento.com.br/contabilidade/modalidades-tributarias 
reduzir ou até eliminar o saldo ou atrasar o recolhimento do tributo por atos ou omissões lícitas do contribuinte, ocorrendo antes do fato gerador. Dito isto, pode-se definir elisão fiscal como a redução de custo tributário lícito.

Saavedra (2013) expressa a elisão fiscal como legítima e lícita, devido a ser alcançada de acordo com o ordenamento jurídico. Portanto, as operações realizadas são aceitas e de conformidade com a lei, não possuindo caráter ilegal. Apesar de que boa parte dos doutrinadores não concordarem que existam lacunas na legislação, deve-se mencionar que as normas brasileiras são minuciosas, tendo em vista as inúmeras modificações que são realizadas por meio de medidas provisórias. Os conjuntos de procedimentos e normas redacionais sugerem que a legislação seja genérica, logo, os casos concretos devem ser aplicados conforme interpretação.

De acordo com Crepaldi e Crepaldi (2017) a elisão fiscal se subdivide em dois grupos, o primeiro grupo trata das disposições decorrentes da lei, pode-se citar como exemplo os incentivos fiscais da Zona Franca de Manaus. Em segundo lugar, pode-se apontar as lacunas que existem na legislação, portanto, são disposições que não são proibidas. Portanto, a classificação apresentada por Crepaldi e Crepaldi (2017) é corroborada por Saavedra (2013). Assim sendo, as operações realizadas são aceitas e de conformidade com a elisão fiscal conforme exposta nessa seção é um procedimento permitido pela legislação e visa auxiliar os empresários na economia de tributos.

É utilizado a evasão fiscal como ato doloso para que se possa evitar a tributação de forma legal. Esses meios lícitos para redução da carga tributária após ocorrência o que se torna diferente em relação a elisão que se utiliza do fato gerador (OLIVEIRA, 2020). Uma maneira comum, muito usada pelos contribuintes é manipular as informações inadequadamente, ao seu favor. Muitas das vezes o contribuinte altera o valor como, por exemplo, de suas receitas, para omitir valores auferidos, para que assim o recolhimento do tributo seja menor. A elisão fiscal aproxima-se do conceito em relação ao planejamento de tributos abusivos, uma vez que está relacionada à manipulação de elementos que se conectam ao contribuinte. O que se torna uma 
vantagem que não é desejada pelo legislador que é vista como uma transgressão aos objetivos do escopo das normas (CALDAS, 2015). Manipular os elementos para obter vantagens, significa violar a norma e pode trazer consequências ao órgão fiscalizador, pois isso significa para o Estado redução das receitas que eles auferem do contribuinte. A evasão fiscal não atinge somente o governo, sua arrecadação ou a empresa que sonega, mas sim a toda a população (NOGUEIRA et al., 2019), afeta a população pelo fato que o Estado deixa de investir já que sua arrecadação prevista se reduziu, pois o Estado depende do contribuinte.

Portanto, o contador dará orientações considerando as normas da legislação fiscal e das normas contábeis que necessitam ser cumpridas obrigatoriamente de forma legal, desta forma evitar tais penalidades financeiras que afetem a entidade, para assim maximizar o lucro.

\subsection{GESTÃO DE PLANEJAMENTO TRIBUTÁRIO}

Este conceito envolve o domínio de tributos, tendo como propósito aumentar o desempenho de uma sociedade empresária. Para tal gestão, faz-se necessário ter ciência das diversas modalidades de tributos que uma companhia deve recolher anualmente, conforme estabelecido na legislação e sem perdas que influenciam de forma negativa a contabilidade do ano-calendário.

Em apartada síntese, pode-se assimilar que este tipo de gestão engloba um conjunto de normas que se adapta no modelo de cada empresa, de forma individual. Sendo norteada pelas atividades econômicas implementadas durante o ano letivo. Diversos fatores podem determinar a carência de uma gestão expert nos setores de competência tributária das companhias: um complexo sistema tributário nacional e um alto ônus fiscal.

Além desses impostos fiscais há outros impostos, por exemplo, o ICMS que é o imposto sobre circulação de mercadorias e prestação de serviços. O custeio bastante exagerado e a burocracia acabam sendo entraves para abrir e 
regulamentar uma empresa no Brasil, já que, os números dos tributos superam outros países que são mais desenvolvidos, isso demonstra que há uma necessidade de mudanças no que diz respeito às regras para abrir uma empresa e na redução da arrecadação dos impostos, principalmente para as pequenas empresas (PAULSEN, 2014).

Segundo Lopes (2017), um dos fatores primordiais para o êxito de uma empresa é a gestão tributária. De acordo com o autor, no país são desenvolvidas cerca de trinta e sete novas legislações tributárias por dia. Neste sentido, as pessoas incumbidas pela gestão de tributos precisam estar sempre atualizadas sobre as normas para que possam manter baixos níveis no que diz respeito ao pagamento de tributos, e com isso diminuir a carga fiscal.

Em síntese, a gestão de tributos inteligente, se torna um método para minimizar o impacto dos tributos no caixa da empresa e que tal gestão sujeita-se ao completo entendimento da legislação aplicável. Assim, sempre que a norma oportuniza a diminuição da carga tributária, a empresa usufrui.

\subsubsection{MODALIDADES TRIBUTÁRIAS}

Conforme estabelecido pelo artigo $3^{0}$ do CTN, tributo possui a concepção de ser uma prestação compulsória em dinheiro feita pelo sujeito passivo da obrigação tributária, em moeda ou cujo valor nela se possa exprimir, não decorrente de penalidade de ato ilícito, desde que estabelecido na legislação e requerido mediante uma atividade da administração que esteja inteiramente ligada. Segundo Sabbag (2014) existe uma compreensão da doutrina harmônica, no qual é defendida a existência de 5 (cinco) tributos no atual sistema tributário brasileiro, tal entendimento decorre da chamada teoria pentapartida.

Neste espeque, as modalidades tributárias são estabelecidas por 2 (dois) ramos diferentes do direito, quais sejam, Direito Tributário e Direito Constitucional. No CTN estão classificadas 3 (três) espécies tributárias, são elas: impostos, taxas e 
contribuições de melhoria. Noutro ponto, a Constituição Federal estabelece outras espécies não mencionadas: empréstimos compulsórios, contribuições sociais interventivas econômicas e contribuições profissionais.

\subsubsection{SIMPLES NACIONAL}

Em 14 de dezembro de 2016 a Lei no 9.317-1996 foi revogada pela Lei Complementar no 123-2006 passando a vigorar o Simples Nacional, cujo propósito era a reunião dos tributos federais, estaduais e municipais, de modo que o contribuinte podia efetivar o pagamento de uma única guia que reunia todos os tributos cobrados possibilitando a reorganização das alíquotas cobradas conforme a atividade desenvolvida pela empresa. No ano de 2016 passou a vigorar a Lei Complementar nำ155-2016, a nova legislação objetivou dentre outras coisas, alterar as alíquotas cobradas e o regulamentar o novo método do cálculo do tributo. Desta forma, este novo método ficou similar com o Imposto de Renda Pessoa Física.

Sendo assim, foram estabelecidos anexos e alíquotas fixas que eram definidas por meio de diversas faixas de faturamento. Desta forma, os segmentos do comércio, indústria e prestação de serviços eram separadas por alíquotas de acordo com a atividade econômica da companhia. Vale ressaltar que também ocorria a separação de enquadramento, de forma que foram divididas as empresas em Microempresa ou Empresa de Pequeno Porte.

Conforme entendimento da Receita Federal Brasil - RFB (2016), o Simples Nacional enquadra-se como um regime tributário peculiar pois além de ser o tipo mais simples, também é aquele tipo que mais favorece o contribuinte se for comparado com os outros regimes. Existem benefícios específicos e estão previstos na Lei Complementar no 123, de 2006, aplicáveis às Microempresas e às Empresas de Pequeno Porte, a partir de 01.07.2007.

O recolhimento do imposto e contribuições é de forma mensal unificada, contendo o Imposto de Renda de Pessoa Jurídica a Contribuição Social sobre o Lucro Líquido 
(CSLL), Contribuição para Financiamento de Seguridade Social (COFINS) dentre outros (OLIVEIRA, 2013).

No artigo apresentado por Paula et al. (2017), apresentam o seguinte entendimento sobre o tema que o Simples Nacional baseado na lei no 9.317 de dezembro de 1996 que foi revogada no dia primeiro de julho de 2007, pois é o Simples Nacional que abrange várias esferas da jurisdição no âmbito Federal e Municipal. Em suma, o Simples nacional é conhecido como uma forma descomplicada de apuração dos impostos, porém, sua forma simplificada não deve camuflar a complexidade da sua interpretação, ou seja, uma empresa pode ser enquadrada em um anexo que não corresponde a atividade de sua empresa devido a uma interpretação errônea da legislação, isso pode provocar o aumento ou redução da carga tributária, o que futuramente poderá trazer consequências significativas para a entidade.

Quadro 1: Simples Nacional

\begin{tabular}{|l|l|l|l|l|l|}
\hline \multirow{2}{*}{$\begin{array}{l}\text { Receita Bruta Total em } 12 \\
\text { meses }\end{array}$} & \multicolumn{4}{|l|}{ Alíquotas } \\
\cline { 2 - 6 } & Comércio & Indústrias & $\begin{array}{l}\text { Serviços } \\
1\end{array}$ & $\begin{array}{l}\text { Serviços } \\
2\end{array}$ & $\begin{array}{l}\text { Serviços } \\
3\end{array}$ \\
\hline Até RS $180.000,00$ & $4,0 \%$ & $4,5 \%$ & $6,0 \%$ & $4,5 \%$ & $15,5 \%$ \\
\hline De $180.000,01$ a $360.000,00$ & $7,3 \%$ & $7,8 \%$ & $11,2 \%$ & $9,0 \%$ & $18,0 \%$ \\
\hline De $360.000,01$ a $720.000,00$ & $9,5 \%$ & $10,0 \%$ & $13,5 \%$ & $10,2 \%$ & $19,5 \%$ \\
\hline De $720.000,01$ a $1.800 .000,00$ & $10,7 \%$ & $11,2 \%$ & $16,0 \%$ & $14,0 \%$ & $20,5 \%$ \\
\hline De $1.800 .000,01$ a $3.600 .000,00$ & $14,3 \%$ & $14,7 \%$ & $21,0 \%$ & $22,0 \%$ & $23,0 \%$ \\
\hline De 3.600.000,01 a $4.800 .000,00$ & $19,0 \%$ & $30,0 \%$ & $33,0 \%$ & $33,0 \%$ & $30,5 \%$ \\
\hline
\end{tabular}

Fonte: Rede Jornal Contábil (2019).

Apesar das tantas alterações que este regime tributário obteve em seu curto tempo de vida, Simples acional se transformou em uma ferramenta importante para as empresas que possuem um porte econômico menor, e aquelas que ainda estão iniciando suas atividades terem mais possibilidades de permanecer no mercado e

RC: 98678

Disponível em:

https://www.nucleodoconhecimento.com.br/contabilidade/modalidades-tributarias 
atuar de forma competitiva com empresas de grande porte e desta forma oferecer um melhor preço no mercado.

\subsubsection{LUCRO PRESUMIDO}

As empresas que não se enquadram no Simples Nacional por auferir uma receita superior a $\mathrm{R} \$ 360.000,00$ (trezentos e sessenta mil reais), podem optar pelo regime Lucro Presumido ou Lucro Real.

Nesse regime, segundo o Decreto 3.000/99 e conforme a Lei 12.814 de 16 de maio de 2013, o montante a ser tributado é determinado com base na receita bruta, através da aplicação de alíquotas variáveis em função da atividade econômica geradora da receita. Segundo Proença e Nogueira (2014) o Lucro Presumido é constituído de forma que a tributação simplificada possa ser exercida pelas empresas de maneira alternativa, que muitas vezes é utilizada por muitos contribuintes como forma de apurar o lucro. Além disso, todo esse sistema é iniciase do total da receita bruta que é aplicada sobre a alíquota que pode ser vista facilmente pela lei brasileira. As pessoas jurídicas que podem optar pelo Lucro Presumido, devem ter receita bruta total no ano-calendário anterior igual ou inferior a $\mathrm{R} \$ 78.000 .000,00$ (Setenta e Oito Milhões) ou ao limite proporcional de $\mathrm{R} \$$ 6.500.000,00 que serão multiplicados pelos 12 meses do ano para se ter o cálculo final. (CAETANO; RIBEIRO, 2017).

Quadro 2: lucro presumido

Lucro Presumido - As alíquotas podem variar de acordo com a atividade

\begin{tabular}{|l|l|l|l|}
\hline $\begin{array}{l}\text { Tributos } \\
\text { Federais }\end{array}$ & Alíquotas & $\begin{array}{l}\text { Tributo } \\
\text { Municipal }\end{array}$ & Alíquota \\
\hline IRPJ & $15 \%$ & ISS & $\begin{array}{l}2 \% \text { a } 5 \% \text { - Varia de acordo } \\
\text { com o município }\end{array}$ \\
\hline CSLL & $9 \%$ & Tributo Estadual & Alíquota \\
\hline COFINS & $3 \%$ & ICMS & $12 \%$ a $18 \%$ - Varia de acordo \\
\hline
\end{tabular}

RC: 98678

Disponível em:

https://www.nucleodoconhecimento.com.br/contabilidade/modalidades-tributarias 


\begin{tabular}{|l|l|l|l|}
\hline & & com o estado \\
\hline PIS & $0,65 \%$ & - & - \\
\hline
\end{tabular}

Fonte: Rede Jornal Contábil (2019).

Esse regime não é vantajoso para as entidades que auferem uma margem de lucro menor do que é estabelecido por lei. Aliás, as arrecadações do PIS e COFINS são obrigatoriamente cumulativas.

\subsubsection{LUCRO REAL}

Além disso, no comparativo em relação aos demais regimes este tem uma apuração ainda mais complexa, pois o imposto de renda é de determinado a partir do lucro contábil, o que vai ser acrescentado de ajustes tanto positivos quanto negativos que passa a ser requerido pela legislação fiscal, dessa maneira, é conceituado como ganho líquido do período de apuração que passa a ser ajustado pelas exclusões, adições ou compensações que podem ser descritas pela lei. As empresas que possuem um faturamento acima de $\mathrm{R} \$ 78$ milhões, estão obrigadas a adotar esta modalidade, pois a determinação será a mesma para cada período de apuração com observância das disposições das leis comerciais (GUTH; AIMI, 2016). As organizações que obtêm um faturamento acima de $R \$ 78$ milhões, estão obrigadas a adotar esta modalidade.

Quadro 3: lucro real

Lucro Real - As alíquotas podem variar de acordo com a atividade

\begin{tabular}{|l|l|l|l|}
\hline $\begin{array}{l}\text { Tributos } \\
\text { Federais }\end{array}$ & Alíquotas & $\begin{array}{l}\text { Tributo } \\
\text { Municipal }\end{array}$ & Alíquota \\
\hline IRPJ & $15 \%$ & ISS & $\begin{array}{l}2 \% \text { a } 5 \% \text { - Varia de acordo } \\
\text { com o município }\end{array}$ \\
\hline CSLL & $9 \%$ & Tributo Estadual & Alíquota \\
\hline COFINS & $7,6 \%$ & ICMS & $12 \%$ a $18 \%$ - Varia de acordo \\
\hline
\end{tabular}

RC: 98678

Disponível em:

https://www.nucleodoconhecimento.com.br/contabilidade/modalidades-tributarias 
com o estado

PIS $\quad 1,65 \%$

Fonte: Rede Jornal Contábil (2019).

Há uma outra forma de vantagem que é o COFINS e PIS que não será acumulativo, mesmo que a alíquota comparativamente ao presumido é maior, e pode haver a probabilidade de descontar créditos. O prejuízo fiscal de um trimestre só poderá deduzir até o limite de $30 \%$ do lucro real dos trimestres seguintes (CREPALDI, 2019).

\subsubsection{SISTEMA TRIBUTÁRIO E CARGA TRIBUTÁRIA BRASILEIRA}

O custeio bastante exagerado e a burocracia acabam sendo entraves para abrir e regulamentar uma empresa no Brasil, pois os números dos tributos superam outros países que são mais desenvolvidos, isso demonstra que há uma necessidade de mudanças nas leis de tributação. Além disso, as empresas precisam cumprir muitas leis que se tornam complexas para elas, e passam assumir o controle dos seus recolhimentos e de outros contribuintes porque o Brasil, por ter uma carga tributária elevada e também bastante complexa, pois a redução dos custos para uma empresa é uma necessidade que visa para ela o alcance de um patamar mais elevado, assim torna-se necessário alternativas lícitas que busquem minimizar isso (CHAVES, 2017).Sabe-se ainda que o governo precisa e vive das arrecadações do contribuinte, que através do recolhimento dos impostos paga-se as contas públicas e todas as despesas que acarretam, como por exemplo os serviços básicos aos cidadãos. A carga fiscal, como também pode-se chamar, nada mais é do que toda a arrecadação anual de tributos pelo governo Federal, Estadual e Municipal. Além disso, há outra problemática que resulta aos cidadãos a terem vários tipos de interpretações, pois ainda há muita falta de conhecimento em relação a ela. Pois o sistema tributário teve reformas desde que foi criado, passando por transformações constantes, levando ao contribuinte manter-se atualizado para não acarretar com punições inesperadas, dado que esse ramo como já foi dito é muito complexo (LIMA; REZENDE, 2017). Por 
esta razão, tem-se um alto custo nos serviços e produtos que adquirimos, visto que as empresas buscam estratégias para terem um diferencial no mercado. Desde o momento que o indivíduo adquire um serviço ou produto tanto de empresas públicas ou privadas, ele já está sendo cobrado indiretamente como também diretamente pelo Estado, pois o imposto já está inserido naquilo que se comprou. Pois cada ente tem autonomia de diversos tributos como por exemplo o ISS é de competência municipal já o ICMS Ihe compete ao estado, sendo assim, cada estado tem a sua própria autonomia sobre seu tributo. Por conseguinte, a grande maioria dos impostos são federais, e são destinados ao Governo Federal.

Quadro 4: Os impostos federais para serviços que são responsáveis por volta do $60 \%$ das arrecadações do país

\begin{tabular}{|l|l|}
\hline & Alíquotas \\
\hline IRPJ & $4,80 \%$ \\
\hline COFINS & $3 \%$ \\
\hline PIS/PASEP & $0,65 \%$ \\
\hline CSLL & $1 \%$ \\
\hline INSS & $11 \%$ \\
\hline
\end{tabular}

Fonte: Rede Jornal Contábil (2019).

Já o destino dos tributos estaduais é para a manutenção administrativa do Governo Estadual, também para o investimento na infraestrutura a nível estadual, dentre elas estão as universidades, escolas como também às rodovias. (JORNAL CONTÁBIL, 2020).

De maneira geral o brasileiro paga muito imposto, no cenário atual um dos temas importantes a serem discutidos é o Sistema Tributário brasileiro, pois ele tem uma imensa complexidade relacionado a carga tributária, pois é de fato muito alta. Se comparar a carga tributária do Brasil com as de outros países que estejam mais ou menos no mesmo nível de desenvolvimento, a carga tributária dele é muito mais 
alta, até mesmo do que as de países muito mais desenvolvidos. Além disso, com os impostos cada vez mais elevados as empresas buscam meios para que possa ocorrer a diminuição dos valores que são pagos, realizando muita das vezes observações internas para que possa identificar a melhor forma de economizar, sem sair das normas e leis vigentes. Entretanto, a falta de conhecimento dos empresários sobre as leis, vêm contribuindo para que aconteça o mal funcionamento das empresas, porque a maioria delas desconhece o que realmente são os tributos que Ihe são cobrados, bem como o impacto sobre os custos dos produtos (LIMA, 2019). Desse modo, a forma como cada um desses tributos é cobrada das corporações varia muito do regime ao qual a organização se insere. Neste caso, as opções que se tornam mais comuns são: simples Nacional; Lucro Real; Lucro Presumido; Lucro Arbitrado. Os impostos que incidem sobre o patrimônio, a renda e o consumo, há também o fator gerador de impostos que estão ligados a uma contraprestação estatal, ou seja, muita das vezes é vinculado a algo que o governo possa oferecer em troca. Ademais, muitas empresas acabam fechando por excesso de tributação e dentro dessa tributação há o PIS e CONFINS, que se torna um emaranhado que muitas das vezes os empresários acabam não entendendo o sistema e assim existem barreiras para que possa sobreviver, principalmente no que diz respeito ao desempenho econômico (MACHADO, 2010; SALES et al., 2011).Porque o Brasil tem o valor que representa $32,36 \%$ do PIB é praticamente um terço do que se produz vai para os cofres públicos em forma de contribuição, no entanto apesar de tamanha contribuição o que pode perceber é que os serviços que são devolvidos à sociedade não são de qualidade, pois há muitos déficits quanto a atendimento hospitalar, educação entre outras coisas, dessa forma existem gastos e mesmo assim o contribuinte ainda precisa desembolsar. Além disso, as empresas pagam mais impostos do que deveriam pagar, pois a primeira coisa a ser feita por uma empresa é a escolha do regime tributário e verificar as projeções as quais darão menos impactos para a empresa. 
Gráfico 1: Carga tributária no Brasil comparada aos outros países

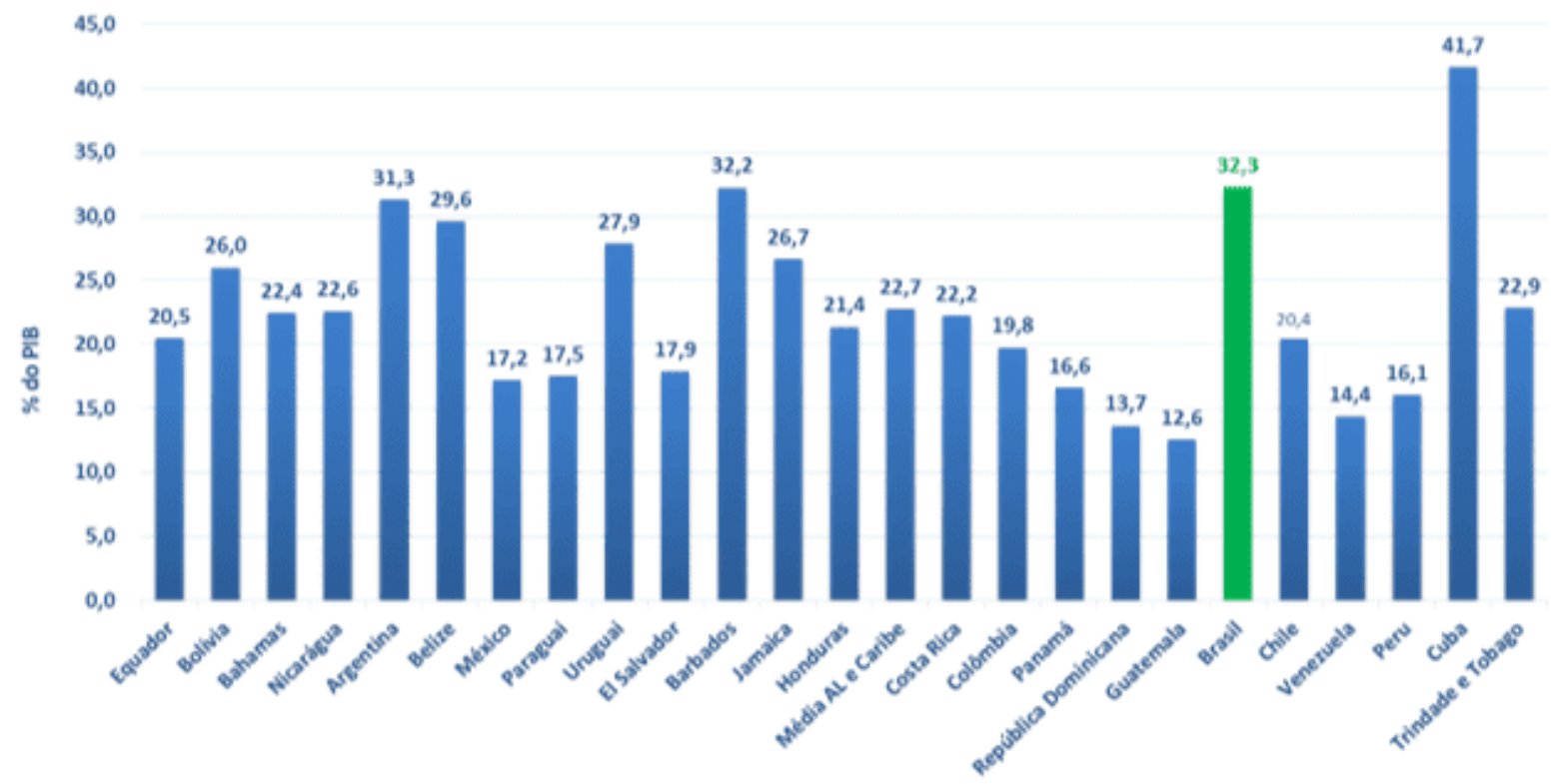

Fonte: Dados da Receita Federal (2017).

No gráfico 1 mostra a carga tributária brasileira comparada a de outros países.

De acordo com Aragão (2017) esclarece que as empresas sofrem com o impacto da alta carga tributária no Brasil, mas que buscam minimizar o efeito do agravante nos seus resultados por meio de técnicas que possam reduzir, extinções ou postergações dos altos custos tributários sejam eles diretos ou indiretos. No cenário atual, que é altamente competitivo, a melhor alternativa para a gestão empresarial é planejar e investir de forma adequada para poder lidar com a carga tributária brasileira. Assim torna-se possível fazer uma gestão tributária eficaz para buscar maneiras contábeis e fiscais que sejam capazes de tornar mais brando o impacto financeiro sobre as operações. Ademais, o bom planejamento tributário, realizado por profissionais que conhecem da área de contabilidade, auxilia de forma direta o processo de tomada de decisão por parte dos gestores e, consequentemente, na evolução do empreendimento. Além disso, é primordial que o seu papel seja muito além de simplesmente apurar os tributos e geração de guias de recolhimento, sendo ele importante também para a evolução de uma rotina de gestão de tributos, que 
possa haver clareza em relação à demonstração das diversificadas possibilidades para gerir situações que a empresa possa enfrentar. No dia a dia das empresas, contar com um bom direcionamento a respeito dos tributos incidentes pode ser um fator de diferencial no que concerne à viabilidade de novos investimentos, uma vez que isso pode ajudar nas escolhas mais adequadas pensando em longo prazo. Além disso, no site da Receita Federal é possível encontrar a carga tributária do Brasil no ano de 2017 onde é demonstrado e analisado os tributos do ano de 2017, que demonstra que a Carga Tributária Bruta atingiu 32,43\% contra 32,29\% em 2016, indicando variação positiva de 0,14 pontos percentuais. (BRASIL, 2017)

Tabela 2: Carga Tributária Bruta

\begin{tabular}{|l|l|}
\hline Componentes 2016 & 2017 \\
\hline Produto Interno Bruto $\mathbf{6 . 2 5 9 , 2 3}$ & $6.559,94$ \\
\hline Arrecadação Tributária Bruta 2.021,16 & $2.127,37$ \\
\hline Carga Tributária Bruta $\mathbf{3 2 , 2 9 \%}$ & $32,43 \%$ \\
\hline
\end{tabular}

Fonte: Brasil (2017).

É possível notar que o PIB de 2017 teve aumento em relação ao ano de 2016. A partir disso, observa-se um crescimento notável e constante em relação aos tributos que são cobrados. Ainda de acordo com a Receita Federal (2017), a carga tributária apresenta aumento pelo terceiro ano consecutivo, atingindo o patamar de $32,43 \%$ do PIB, ainda aquém dos 33,66\% observado em 2007, antes da crise econômica de 2008. Dessa maneira, é perceptível o quão importante é para empresa e para o dono dela planejar bem, pois o bom planejamento tributário contribui de maneira significativa para o crescimento e desempenho da corporação, pois para ela quando não conseguem repassar toda a carga tributária a seus preços, o resultado líquido decresce, interferindo em sua capacidade de investimentos, até mesmo na reposição dos níveis já alcançados (GALLO, 2010), assim torna-se essencial que ocorra esse planejamento para que ela não decresça, mas cresça. Porque a empresa visa o lucro e o melhor gasto e investimento, assim é essencial analisar as 
condições empresarial, pois a competitividade é muito alta, e assim muita das vezes também é necessário diminuir gastos para que se tenha bons lucros, pois todo sistema tangível, como um empreendimento com fins lucrativos, tem pelo menos uma restrição.

\section{MATERIAIS E MÉTODOS}

O método significa o caminho por qual seguir mediante séries de operações e regras pré-fixadas para assim poder alcançar os resultados propostos. Visto que, a metodologia segue algumas etapas, por isso dependerá do pesquisador quais métodos e materiais serão utilizados em sua investigação. Diante disso, no entendimento de a metodologia se define, de maneira operacional, como o estudo crítico do método, ou bem como a lógica particular de uma disciplina (SANTANCHÉ, 2015).

Por isso, esta pesquisa utilizará métodos, técnicas e instrumentos que facilitarão a execução do trabalho. Para assim facilitar o entendimento ao leitor referente ao planejamento de tributos e as modalidades tributárias que serão discutidos ao decorrer do estudo.

\subsection{PROCEDIMENTOS METODOLÓGICOS}

Os procedimentos metodológicos trata-se da escolha do método e a forma da pesquisa que será utilizada. Sendo que este estudo, valeu-se de dados e informações em fontes bibliográficas, tendo como objetivo demonstrar a maneira que o planejamento de tributos contribui positivamente no resultado financeiro das organizações. Para Menezes et al. (2019) os procedimentos metodológicos são procedimentos detalhados do que serão abordados ao realizar o estudo.

\subsubsection{QUANTO À NATUREZA}

Há dois tipos de investigação, a qualitativa e a quantitativa, ambas são fundamentais na escrita da metodologia de um projeto, pois mostram que os direcionamentos que

RC: 98678

Disponível em:

https://www.nucleodoconhecimento.com.br/contabilidade/modalidades-tributarias 
o estudo tomará no decorrer do seu desenvolvimento (MENEZES et al., 2019). A pesquisa a ser realizada nesta pesquisa é de natureza qualitativa, pois serão coletados dados em diversos tipos de fontes bibliográficas, compilando informações relevantes que estejam em concordância com o que será abordado no decorrer da pesquisa.

\subsubsection{QUANTO AOS FINS}

Toda pesquisa realizada possui um propósito em relação ao que foi estabelecido no decorrer do desenvolvimento da proposta de estudo, dessa maneira, trata-se de pesquisa descritiva que tem como objetivo descrever todos os problemas encontrados ao decorrer da pesquisa. De acordo com Vergara (2016) a pesquisa descritiva mostra características de uma determinada população e um determinado fenômeno porque visa reunir informações relacionadas ao planejamento tributário para que as empresas possam saber qual regime é o mais favorável de acordo com sua atividade econômica.

\subsubsection{QUANTO AOS MEIOS}

Os estudos quanto aos meios têm como principal foco analisar os problemas que são encontrados no decorrer do estudo que serão solucionados ou não porque os meios para alcançar os resultados da investigação são diversos, conforme Severino (2013). A partir do desenvolvimento do estudo é um estudo qualitativo descritivo que tem como foco o planejamento tributário o mais favorável econômico para empresa.

\section{CONSIDERAÇÕES FINAIS}

Através deste estudo observou-se que as empresas de pequeno porte e as microempresas, devem enquadrar-se no Simples Nacional pelo fato que o seu lucro auferido é inferior comparando com as demais modalidades. Pois, é gerado uma guia de arrecadação, aliás as alíquotas de impostos a serem recolhidos são calculados conforme o faturamento de cada atividade, para isso é preciso 
contabilizar a receita bruta e logo verificar na tabela, porém o faturamento anual dessas organizações é menor o que pode gerar vantagens em relação aos impostos que serão pagos pela empresa.

Ainda foi visto que Lucro Real a apuração do IRPJ e CSLL é complexa, e ao final, algumas vezes poderá haver prejuízo fiscal, onde não haverá impostos a serem recolhidos. Pois um ponto positivo é que podem abater os créditos do PIS e COFINS, pois no arbitrado não há essa possibilidade.

Contudo, não basta apenas ter todas essas informações citadas acima, a qual leva a necessidade do auxílio e orientação de um contador tributarista, já que este tem o conhecimento da legislação, pois ele analisará todas as informações geradas e fornecidas pela empresa, levando-o a indicar qual a melhor modalidade a que ela se enquadra. Com relação a questão norteadora do trabalho sobre: como o planejamento tributário pode ajudar o contribuinte na escolha das modalidades tributárias no simples nacional, lucro presumido e lucro real? Sendo respondida da seguinte maneira: à medida que se pode identificar a partir do estudo realizado que o correto planejamento tributário auxilia na prevenção de erros contábeis e evita possíveis multas por parte do fisco se o contribuinte deixar de pagar os impostos e tributos, também auxilia na saúde financeira da empresa.

Dito isto, com este estudo elaborado espera-se que sirva como ferramenta para que as empresas tenham acesso a mais informações atualizadas, pois sabe-se que sempre há ajustes tributários, por isso é fundamental avaliar se as características do regime tributário se encaixam ao perfil da empresa. Portanto, o estudo evidenciou os aspectos da carga tributária, lucro real, presumido, elisão fiscal e identificou a partir do estudo qual seria a melhor opção de escolha para o empresário aderir.

\section{REFERÊNCIAS}

ARAGÃO, J. W. M. de; NETA, M. A. H. M. Metodologia Científica. Salvador: UFBA, Faculdade de Educação, Superintendência de Educação a Distância, 2017.

RC: 98678

Disponível em:

https://www.nucleodoconhecimento.com.br/contabilidade/modalidades-tributarias 
BRASIL. CÓDIGO DE TRIBUTÁRIO NACIONAL. Lei no 5. 172, de 25 de outubro de 1966.

<http://www.receita.fazenda.gov.br/Legislacao/CodTributNaci/ctn.htm>. Acesso em: 1 maio. 2021.

BRASIL. Decreto n. 3.000, de março de 1999. Regulamenta a tributação, fiscalização, arrecadação e administração do Imposto sobre a Renda e Proventos de Qualquer Natureza.

Disponível

em: <https://www.legisweb.com.br/legislacao/?id=53754>. Acesso em: 14 maio 2021.

BRASIL. Lei n. 12.814, de maio de 2013. Disponível em: $<$ https://www.in.gov.br/materia//asset_publisher/Kujrw0TZC2Mb/content/id/30039328/do1-2013-05-17-lei-no-12814-de-16-de-maio-de-2013-30039314>. Acesso em: 22 set. 2021.

BRASIL. Lei no 123, de 14 de dezembro de 2006. Disponível em: <http://www.comprasnet.gov.br/legislacao/leis/lei123_2006.htm>. Acesso em: 23 ago. 2021.

BRASIL. Lei no 6.404 de 15 de dezembro de 1976. Disponível em: <https://www.jusbrasil.com.br/topicos/11499295/artigo-153-da-lei-n-6404-de-15-dedezembro-de-1976>. Acesso em: 30 ago. 2021.

BRASIL. Carga Tributária Bruta, 2017. Disponível em: $<$ https://www.gov.br/receitafederal/pt-br/assuntos/noticias/2018/dezembro/cargatributaria-bruta-atingiu-32-43-do-pib-em-2017>. Acesso em: 30 de ago. 2021

BRASIL. Instituto Brasileiro de Planejamento e Tributação, 2011. Disponível em: <http://www.portaltributario.com.br/planejamento.htm>. Acesso em: 22 de set. 2021

BRASIL. Lei no 9.317 de 5 dezembro de 1996. Disponível em: $<$ https://jus.com.br/artigos/10081/lei-n-9-317-1996-simples-x-lei-complementar-n123-2006-simples-nacional>. Acesso em: 22 de set. 2021

RC: 98678

Disponível em:

https://www.nucleodoconhecimento.com.br/contabilidade/modalidades-tributarias 
BRASIL. Lei no155 de 27 outubro de 2016. Disponível em: $<$ https://www2.camara.leg.br/legin/fed/leicom/2016/leicomplementar-155-27-outubro2016-783850-publicacaooriginal-151329-pl.html> Acesso em: 21 de set. 2021

CAETANO, V. B.; RIBEIRO, R. B. Planejamento tributário em empresa de construção civil: benefícios proporcionados pelo regime especial de tributação. RAGC, v. 5, n. 18, 2017.

CALDAS, M. O Conceito de Planejamento Fiscal Agressivo: Novos Limites ao Planejamento Fiscal? Cadernos IDEEF n.18. Coimbra: Almedina, 2015.

CHAVES, F. C. Planejamento Tributário na Prática: Gestão Tributária Aplicada. 4 ED. São Paulo: Atlas, 2017.

CREPALDI, S. A.; CREPALDI, G. S. Contabilidade Fiscal e Tributária: Teoria Prática. 2 ed. São Paulo: Saraiva, 2017.

CREPALDI, S. Planejamento Tributário: Teoria e Prática. 3 ed. São Paulo: Saraiva Educação, 2019.

GALLO, M. F. A relevância contábil na mensuração da carga tributária das empresas. Tese (Doutorado em Ciências Contábeis) - Programa de Pós Graduação em Controladoria e Contabilidade, Universidade de São Paulo, 2010.

GRAZIOSE, M.; LIEBANO, R. Elaboração da Pergunta Norteadora de Pesquisa. São Paulo: UNIFESP, Universidade Federal de São Paulo, 2010.

GUTH, S. C.; AIMI, M. J. A Agroindústria e a Tributação do lucro real anual na opção de pagamento mensal do imposto por estimativa, com ênfase no balanço ou balancete de suspensão/redução. In: II SIMPÓSIO, 2016.

JORNAL CONTÁBIL. Lucro Arbitrado: Entenda como é e como funciona. 2019. Disponível em: <https://www.jornalcontabil.com.br/lucro-arbitrado-entenda-o-que-ee-como-funciona/>. Acesso em: 22 ago. 2021.

RC: 98678

Disponível em:

https://www.nucleodoconhecimento.com.br/contabilidade/modalidades-tributarias 
LIMA, D. A. de. Recuperação de crédito tributário no Simples Nacional. 26/Nov/2019.

$<$ https://www.direitonet.com.br/artigos/exibir/11410/Recuperacao-de-credito-no-

Simples-Nacional\#: :text=Ap\%C3\%B3s\%20a\%20apura>. Acesso em: 30 ago. 2021.

LIMA, E. M.; REZENDE, A. J. Um estudo sobre a evolução da carga tributária no Brasil: uma análise a partir da Curva de Laffer. Interações (Campo Grande), v. 20, n. 1, 2017.

LOPES, A. C. T. L. O papel do contador na gestão tributária dos pequenos empreendimentos. 2017.

Disponível em:

$<$ https://www.contabeis.com.br/artigos/489/o-papel-do-contador-na-gestaotributariadospequenos-empreendimentos>. Acesso em: 26 maio 2021.

MACHADO, H. V. Empreendedorismo e franchising: uma combinação que garante a sobrevivência? Revista de Administração Mackenzie, São Paulo, v. 11, n. 4, 2010.

MENEZES, A. H. N.; et al. Metodologia científica: teoria e aplicação na educação a distância. Universidade Federal do Vale do São Francisco, Petrolina-PE, 2019.

NOGUEIRA, G. O. J. M.; et al. Planejamento tributário agressivo como forma de capitalização por meio do Refis: um estudo em uma empresa familiar. Revista Controle-Doutrina e Artigos, v. 17, n. 2, p. 259-282, 2019.

OLIVEIRA, G. P. de. Contabilidade tributária. 3. ed. São Paulo: Saraiva, 2013.

OLIVEIRA, R. R. F. de. Offshore como Estratégia de Planejamento Tributário. Brazilian Applied Science Review, V.4. n.5, p. 3043-3051, 2020.

PAULSEN, L. Curso de Direito Tributário. 6 a $^{\mathrm{a}}$ ed. Porto Alegre: Livraria do Advogado, 2014. 
PAULA, R. M.; et al. A Percepção da Carga Tributária nas Micro e Pequenas Empresas antes e após o Simples Nacional. REVISTA DA MICRO E PEQUENA EMPRESA, v. 11, n. 1, p. 34- 51, 2017.

PROENÇA, F. R.; NOGUEIRA, D. R. Planejamento tributário. Londrina: UNOPAR, 2014.

SALES, R. L.; et al. Fatores condicionantes da mortalidade dos pequenos negócios em um típico município interiorano brasileiro. Revista do micro e pequena empresa, v. 5, 2011.

SABBAG, E. Manual de Direito Tributário. 6. Ed. São Paulo: Saraiva, 2014.

SAAVEDRA, M. V. Elisão e Evasão fiscal. JusBrasil, 2013. Disponível em:<https://marcus-saavedra.jusbrasil.com.br/artigos/111686325/elisao-e-evasaofiscal> Acesso em: 24 de maio de 2021.

SANTANCHÉ, A. Construção do Conhecimento e Metodologia Científica. Jaboatão dos Guararapes-PE: UNIGF, 2015.

SEVERINO, A. J. Metodologia do trabalho científico. 24. ed. São Paulo: Cortez, 2013.

SIMPLES NACIONAL. Receita Federal do Brasil, Brasília, 2016. Disponível em: <http://www8.receita.fazenda.gov.br/SimplesNacional/Perguntas/Perguntas.aspx>. Acesso em: 24 de maio. 2021.

VELLO, A. P. C.; MARTINEZ, A. L. Planejamento tributário eficiente: uma análise de sua relação com o risco de mercado. Revista Contemporânea de Contabilidade, v. 11, n. 23, p. 117-140, 2014.

VERGARA, S. C. Projetos e Relatórios de Pesquisa em Administração. 16 ed. São Paulo: Atlas, 2016. 
Enviado: Setembro, 2021.

Aprovado: Outubro, 2021. 